\title{
Vivenciando o prazer da leitura
}

\author{
Mariangela Tschisar \\ e037813a@see.sp.gov.br \\ E. E. Prof. Didio da Silveira Baldy - São Paulo - SP - Brasil
}

\section{Resumo}

A E.E.Professor Dídio da Silveira Baldy está localizada na Vila Tolstoi, na Zona Leste da cidade de São Paulo. Atende alunos do $1^{\circ}$ ao $5^{\circ}$ anos do Ensino Fundamental - Anos Iniciais. Através da análise dos dados do IDEB e IDESP da escola observamos que um elevado número de alunos encontra-se abaixo do nível adequado tanto em Língua Portuguesa quanto em matemática. As maiores dificuldades encontram-se na leitura, interpretação textual e escrita dos alunos. Os professores enfrentam dificuldades em aplicar novas metodologias e estratégias de ensino para desenvolver as habilidades necessárias aos alunos. Constatou-se também pouco acompanhamento dos pais na rotina escolar dos filhos.

Para sanar essas dificuldades, a equipe escolar decidiu pela elaboração de um projeto que enfoque a melhoria da leitura e escrita dos alunos, capacitação de professores e comprometimento das famílias na rotina escolar dos alunos. As principais ações desenvolvidas serão: reuniões pedagógicas e de capacitação com a equipe escolar, palestra de conscientização para os pais, aplicação de novas estratégias e metodologias de ensino nas aulas e oficinas de leitura com alunos e pais.

Os objetivos estratégicos do projeto são: aumentar o nível de desempenho dos alunos em Língua Portuguesa e Redação, aumentar o acompanhamento dos pais na rotina escolar dos filhos e capacitar os professores para utilizarem novas metodologias e estratégias diversificadas de ensino.O PLEM deverá ser executado por um período de três anos consecutivos. O valor total do Plano de Investimento para esse período será de R $\$$ $75.948,00$ (utilizado para compra de material permanente, de consumo e serviços de terceiros) com contrapartida de $\mathrm{R} \$ 40.113,00$.

Palavras-chaves: Plano de Empreendimento. Oficinas de leitura. Leitura e escrita. Gestão empreendedora na Educação. 


\section{Caracterização da Escola}

A Escola Estadual Prof. Didio da Silveira Baldy, localizada em São Paulo (SP), foi fundada em 1977 e atende ao Ensino Fundamental I. A escola tem como missão oferecer um ensino de qualidade que possibilite 0 desenvolvimento do senso crítico, respeitando e valorizando o ser humano em seus princípios éticos fundamentais: igualdade, liberdade, solidariedade, participação e diversidade com as principais estratégias de ação: busca constante de aperfeiçoamento, tendo a aprendizagem como processo contínuo de aquisição do saber; cooperação, melhorando a comunicação e buscando a participação e 0 desenvolvimento do ser humano, da escola e da comunidade; visão consciente e crítica da realidade e a visão de "ser reconhecida como uma escola que favorece o desenvolvimento integral do educando, desenvolve o senso crítico e resgata a cidadania, formando cidadãos conscientes de seu papel na sociedade".

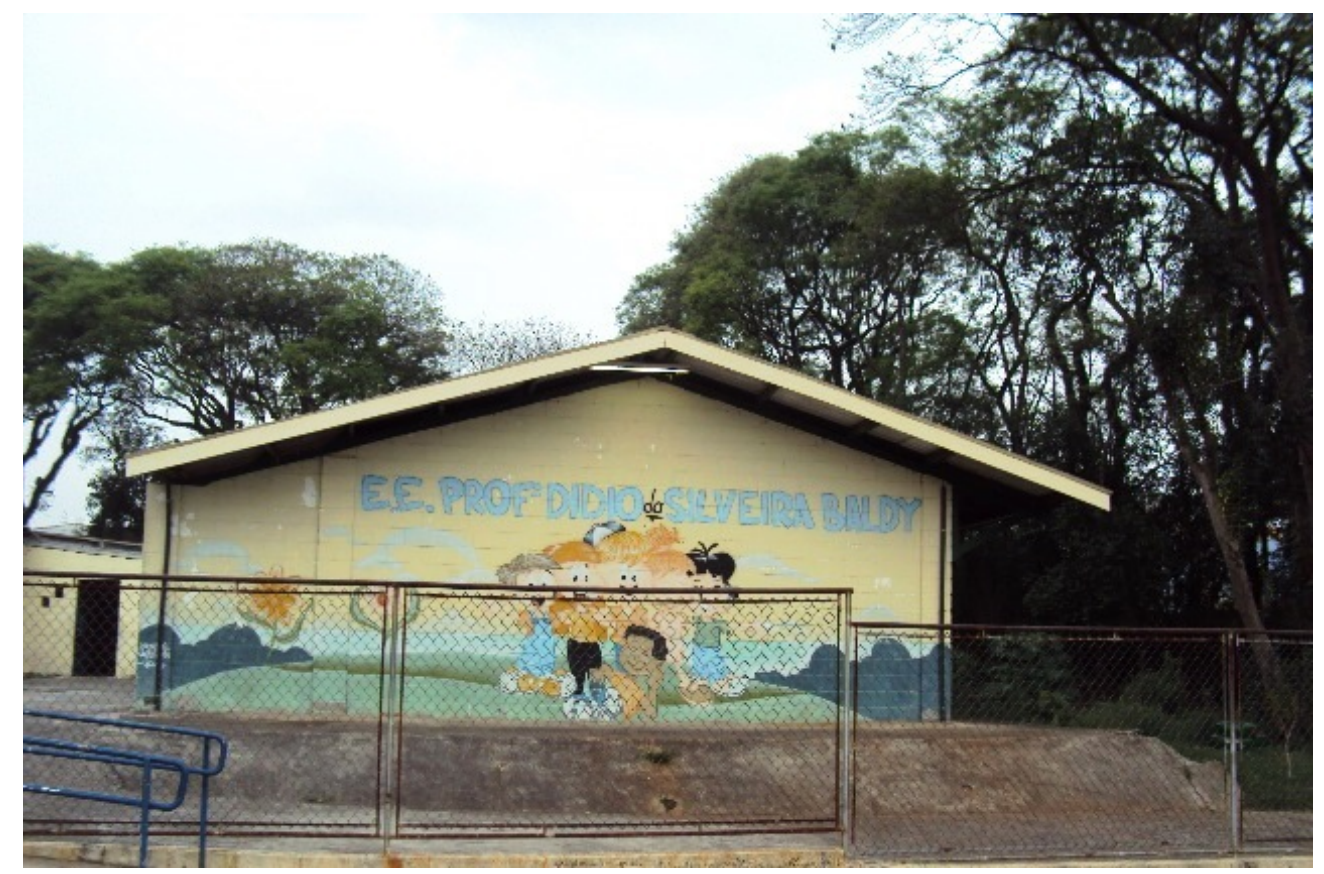

\section{Instalações}

A edificação da escola possui apenas o nível térreo. Todas as instalações encontram-se em bom estado de conservação, pois passou por reforma geral no ano de 2012, onde houve troca de pisos, pintura geral, manutenção da parte hidráulica e elétrica e reforma total dos banheiros dos alunos. A escola possui 15 salas de aula, laboratório de informática com computadores novos, sala de vídeo, refeitório, brinquedoteca, duas quadras, uma coberta e outra descoberta, duas cozinhas sendo uma para preparação da merenda escolar e a outra para os funcionários, sala da direção, sala da gerência escolar, sala da coordenação, secretaria, dois sanitários de alunos sendo um masculino e outro feminino, dois sanitários de funcionários sendo um masculino e outro feminino, depósito de material de limpeza, depósito de merenda escolar e depósito de material pedagógico. Possuímos na área externa um grande bosque e playground com brinquedos para utilização dos alunos.

\section{Breve histórico}

O quadro a seguir apresenta a relação dos acontecimentos mais relevantes para a evolução da escola, desde a fundação até hoje. 


\begin{tabular}{|l|l|}
\hline Ano & Acontecimentos relevantes \\
\hline 1977 & $\begin{array}{l}\text { Fundação da Escola - EE Prof. Didio da Silveira Baldy atendendo alunos da } \\
1^{\mathrm{a}} \text { à } 8^{\mathrm{a}} \text { série }\end{array}$ \\
\hline 1990 & Ampliação do prédio com a construção de 7 novas salas de aula \\
\hline 1995 & Reorganização da escola atendendo alunos da $1^{\mathrm{a}}$ à $4^{\mathrm{a}}$ série \\
\hline 2006 & Reorganização atendendo os anos iniciais $-1^{0}$ ao $5^{\circ}$ ano \\
\hline $2012 / 13$ & Reforma geral do prédio escolar, com ênfase em acessibilidade \\
\hline
\end{tabular}

\section{Professores e funcionários}

A equipe é formada por 34 professores, distribuídos da seguinte forma:

\begin{tabular}{|l|l|}
\hline Disciplina / Área & Quant. de professores \\
\hline PEB I - Magistério / Pedagogia & 27 \\
\hline Arte & 02 \\
\hline Educação Física & 04 \\
\hline PEB II - Matemática (readaptado) & 01 \\
\hline
\end{tabular}

Do total de professores, 18 são professores efetivos, 01 é professor readaptado, 06 são professores OFA (Ocupantes de Função Atividade) e 09 contratados. Desses professores, 10 possuem menos de cinco anos de experiência na rede, 06 possuem de cinco a dez anos na rede e 18 possuem mais de dez anos. Quanto ao nível de formação 06 professores têm Formação em Magistério e o restante é graduado em Pedagogia, Arte, Matemática ou Educação Física. Além disso, a escola conta com 18 funcionários de apoio, sendo 01 Gerente de Organização Escolar, 09 Agentes de Organização, 02 Agentes de Serviços Gerais readaptados, 03 Preparadores de Merenda (terceirizados) e 03 Agentes de Serviços Gerais (terceirizados).

\section{Perfil dos alunos}

Os alunos estão distribuídos por séries e turnos da seguinte maneira:

\begin{tabular}{|c|c|c|c|c|c|c|c|c|}
\hline \multirow[b]{2}{*}{ Série/Ano } & \multirow{2}{*}{$\begin{array}{l}\text { Média } \\
\text { de } \\
\text { idade }\end{array}$} & \multirow{2}{*}{$\begin{array}{l}\text { Total } \\
\text { de } \\
\text { alunos }\end{array}$} & \multicolumn{2}{|l|}{ Manhã } & \multicolumn{2}{|l|}{ Tarde } & \multicolumn{2}{|l|}{ Noite } \\
\hline & & & $\begin{array}{l}\mathrm{N}^{0} \\
\text { alunos }\end{array}$ & $\begin{array}{l}N^{0} \\
\text { turmas }\end{array}$ & $\begin{array}{l}\mathrm{N}^{0} \\
\text { alunos }\end{array}$ & $\begin{array}{l}\mathrm{N}^{0} \\
\text { turmas }\end{array}$ & $\begin{array}{l}\mathrm{N}^{0} \\
\text { alunos }\end{array}$ & $\begin{array}{l}\mathrm{N}^{0} \\
\text { turmas }\end{array}$ \\
\hline $1^{0}$ ano & 6,8 & 179 & 88 & 03 & 91 & 03 & - & - \\
\hline $2^{\circ}$ ano & 7,7 & 167 & 77 & 03 & 90 & 03 & - & - \\
\hline $3^{0}$ ano & 8,9 & 153 & 61 & 02 & 92 & 03 & - & - \\
\hline $4^{0}$ ano & 9,8 & 140 & 62 & 02 & 78 & 03 & - & - \\
\hline $5^{\circ}$ ano & 10,9 & 152 & 68 & 02 & 84 & 03 & & \\
\hline TOTAL & - & 791 & 356 & 12 & 435 & 15 & & \\
\hline
\end{tabular}

A maioria dos alunos reside perto da escola, quase inexistindo problemas com locomoção. Cerca de $30 \%$ dos alunos são filhos de famílias de nível sócio econômico baixíssimo. Muitos cuidam dos irmãos menores para que as mães possam trabalhar. Muitas famílias são chefiadas por mães ou avós em virtude de separações entre casais ou são mães solteiras. Cerca de $20 \%$ incluem-se na classe média, residindo em casas com melhor estrutura física, possuindo bens de consumo modernos. Recebem maior atenção e cuidado dos responsáveis, praticam atividades como futebol, natação, aulas de informática, etc.

A maioria dos alunos participa das atividades desenvolvidas pela escola como festas, mostras culturais, exposições, oficinas de pintura, oficinas de reciclagem, teatro, etc. Apesar de termos uma participação significativa dos pais nessas atividades, um dos maiores problemas que encontramos é a pouca participação dos pais no acompanhamento da vida escolar dos filhos.

Quanto ao comportamento dos alunos, temos casos pontuais de indisciplina, sendo os alunos e pais 
orientados pelos professores e gestores da escola. Trabalhamos com um enfoque preventivo e com 0 conceito de "limites", enfatizando sempre a necessidade do auxílio da família.

\section{Características do entorno}

No bairro há um extenso comércio com mercados, bancos, lojas, restaurantes e pequenas indústrias. Nas imediações existem outras escolas da prefeitura que atendem o Ensino Fundamental ( $1^{\circ}$ ao $9^{\circ}$ ano) e escolas estaduais que atendem os anos finais ( $6^{\circ}$ ao $9^{\circ}$ ano) e Ensino Médio.

Na região próxima à escola existem diversas praças destinadas a atividades de lazer, pistas de caminhada, quadras de futebol e basquete, ciclovias, playground para crianças com escorregador, balanços e gangorra.

Os índices de violência da região são elevados, assim como o tráfico de entorpecentes. 0 sistema de transportes é grande e conta com várias linhas de ônibus, avenidas e o Monotrilho que está em fase final de construção.

\section{Identificação do problema e da oportunidade}

A identificação do problema partirá de um diagnóstico da Unidade Escolar. Para isso, foram observadas as principais avaliações externas, avaliações da equipe pedagógica, bem como relatórios internos de desempenho.

\section{IDEB}

Observando os dados do IDEB, verificamos que a escola na prova Brasil obteve um aumento crescente dos resultados em 2009, 2011 e 2013. O IDEB de 2013 foi de 6,3. Apesar desse resultado, 20\% dos alunos que realizaram a prova apresentam ainda índice insuficiente de proficiência em língua portuguesa. Em matemática, o percentual de alunos nos níveis abaixo do básico e básico, juntos, chega a $41,32 \%$ dos alunos. Necessitamos aprimorar o trabalho com os conteúdos, habilidades e competências para aumentar significativamente a porcentagem de alunos nos níveis adequado e avançado.

\section{Resultado IDEB para $4^{\mathrm{a}}$ série $/ 5^{\circ}$ ano}

\begin{tabular}{|l|l|l|l|l|l|l|l|l|l|}
\hline ANO & $\mathbf{2 0 0 5}$ & $\mathbf{2 0 0 7}$ & $\mathbf{2 0 0 9}$ & $\mathbf{2 0 1 1}$ & $\mathbf{2 0 1 3}$ & $\mathbf{2 0 1 5}$ & $\mathbf{2 0 1 7}$ & $\mathbf{2 0 1 9}$ & $\mathbf{2 0 2 1}$ \\
\hline $\begin{array}{l}\text { Metas } \\
\text { projetadas }\end{array}$ & - & - & 5,4 & 5,7 & 5,9 & 6.1 & 6.4 & 6,6 & 6,8 \\
\hline Ideb observado & - & 5,2 & 5,6 & 5,7 & 6,3 & - & - & - & - \\
\hline
\end{tabular}

Fonte: INEP

\section{Avaliação estadual}

No SARESP, a escola obteve um nível de aproveitamento superior a média da Diretoria de Ensino Leste $4 \mathrm{e}$ do Estado de São Paulo, com IDESP de 5,16\%. Conseguimos apresentar bom desempenho em língua portuguesa e matemática. A maior dificuldade dos alunos foi na interpretação do enunciado das questões. $A$ escola ainda possui um alto índice de alunos que encontram-se abaixo do nível adequado tanto em Língua Portuguesa $(39,86 \%)$ quanto em matemática $(51,75 \%)$.

\section{SARESP}

\begin{tabular}{|c|c|c|c|c|c|}
\hline \multicolumn{6}{|r|}{ ILVEIRA } \\
\hline ANO & DISCIPLINA & ABAIXO DO BÁSICO & BÁSICO & $\begin{array}{l}\text { ADEQUAD } \\
0\end{array}$ & AVANÇADO \\
\hline \multirow{2}{*}{$\begin{array}{l}5^{\circ} \\
\text { ano } \\
\text { EF }\end{array}$} & LIINGUA PORTUGUESA & $10,49 \%$ & $29,37 \%$ & $42,66 \%$ & $17,48 \%$ \\
\hline & MATEMÁTICA & $14,69 \%$ & $37,06 \%$ & $35,66 \%$ & $12,59 \%$ \\
\hline
\end{tabular}




\begin{tabular}{|c|c|c|c|c|c|}
\hline \multicolumn{6}{|c|}{ IDESP 2014 - INDICADORES DA ESCOLA - EE PROF. DIDIO DA SILVEIRA BALDY } \\
\hline \multirow[b]{2}{*}{ ANO } & \multicolumn{2}{|c|}{ INDICADORES DE DESEMPENHO } & \multirow{2}{*}{$\begin{array}{l}\text { INDICADOR DE } \\
\text { DESEMPENHO }\end{array}$} & \multirow{2}{*}{$\begin{array}{l}\text { INDICADOR } \\
\text { DE FLUXO }\end{array}$} & \multirow[b]{2}{*}{ IDESP 2014} \\
\hline & $\begin{array}{l}\text { LÍNGUA } \\
\text { PORTUGUESA }\end{array}$ & MATEMÁTICA & & & \\
\hline $\begin{array}{l}5^{\circ} \text { ano } \\
E F\end{array}$ & 5,5710 & 4,8717 & 5,22 & 0,9886 & 5,16 \\
\hline
\end{tabular}

\section{EVOLUÇÃO E CUMPRIMENTO DAS METAS DE 2014, POR CICLO ESCOLAR EE PROF. DIDIO DA SILVEIRA BALDY}

\begin{tabular}{|l|l|l|l|l|}
\hline ANO & $\begin{array}{l}\text { IDESP } \\
\mathbf{2 0 1 3}\end{array}$ & IDESP 2014 & $\begin{array}{l}\text { METAS } \\
\mathbf{2 0 1 4}\end{array}$ & ÍNDICE DE CUMPRIMENTO (IC) \\
\hline $\begin{array}{l}\mathbf{5}^{\circ} \\
\text { ano } \\
\text { EF }\end{array}$ & 4,84 & 5,16 & 4,97 & 120,00 \\
\hline
\end{tabular}

Observação: Realizamos apenas avaliações referentes à Língua Portuguesa e Matemática.

\section{Avaliações e relatórios internos}

\section{FLUXO ESCOLAR 2014 - EE PROF. DIDIO DA SILVEIRA BALDY}

\begin{tabular}{|l|l|l|l|l|l|l|}
\hline Série/Ano & $\begin{array}{l}\text { Matrículas } \\
\text { iniciais }\end{array}$ & Evasão & Transf. & $\begin{array}{l}\text { Matrículas } \\
\text { finais }\end{array}$ & Aprov. & Reprov. \\
\hline $1^{\circ}$ ano & 230 & 01 & 54 & 175 & 174 & 01 \\
\hline $2^{\circ}$ ano & 189 & 00 & 32 & 157 & 157 & 00 \\
\hline $3^{\circ}$ ano & 177 & 00 & 17 & 160 & 157 & 03 \\
\hline $4^{\circ}$ ano & 195 & 00 & 30 & 165 & 164 & 01 \\
\hline $5^{\circ}$ ano & 181 & 00 & 26 & 155 & 152 & 03 \\
\hline
\end{tabular}

Analisando o Fluxo escolar do ano letivo de 2014, observamos que a escola possui excelentes índices de evasão e aprovação. Fazemos um trabalho contínuo de monitoramento das faltas dos alunos. Os pais são convocados para justificar as faltas em excesso, e caso seja necessário fazemos a compensação de ausências com atividades ministradas pelos professores. Os casos mais graves são encaminhados ao Conselho Tutelar.

A equipe escolar fez uma análise dos resultados das avaliações internas. No ano de 2014, utilizamos avaliações diagnósticas com a compilação de dados na Plataforma Meritt e neste ano de 2015 foram realizadas duas avaliações diagnósticas (AAP), onde utilizamos a plataforma SARA, que nos proporcionou uma maior compilação de dados com a análise dos resultados de cada turma. Pode se verificar as dificuldades de cada uma e as habilidades que deverão ser trabalhadas pelos professores em Língua Portuguesa e Matemática.

Foram também discutidos os resultados das avaliações processuais e contínuas trabalhadas pelos professores durante o ano letivo, comparando os resultados com os da Plataforma SARA.

As principais ações a serem desenvolvidas serão:

- Aplicação de novas estratégias e metodologias de ensino para trabalhar as dificuldades dos alunos em Língua Portuguesa;

- Capacitação dos professores;

- Elaboração de Projeto de Leitura e Escrita, incluindo professores, alunos e pais (para um melhor acompanhamento da rotina escolar dos filhos), utilizando espaços e acervos literários da escola. 


\section{Principais problemas identificados}

Um dos principais problemas está na leitura e escrita e na interpretação de textos, tanto em língua portuguesa quanto em matemática. Os alunos com muita dificuldade são encaminhados para as aulas de reforço escolar.

0 professor também enfrenta dificuldades em aplicar novas metodologias e estratégias para desenvolver as habilidades necessárias aos alunos e precisa de capacitação constante. Utiliza pouco a sala de informática, brinquedoteca, sala de vídeo e acervo de livros da escola.

Constatamos também pouco acompanhamento dos pais na vida escolar do aluno, sendo a escola um dos únicos ambiente de aprendizagem dos alunos.

\section{Matriz GUT - Priorização dos problemas}

\begin{tabular}{|l|l|l|l|l|l|}
\hline Problemas & G & U & T & GxUxT & Prioridade \\
\hline Dificuldades do aluno na leitura e escrita. & 5 & 5 & 5 & 125 & $1^{0}$ \\
\hline Necessidade de capacitação dos professores & 5 & 5 & 4 & 100 & $2^{0}$ \\
\hline Participação dos pais na rotina dos filhos & 4 & 3 & 3 & 36 & $3^{0}$ \\
\hline $\begin{array}{l}\text { Pouca utilização dos espaços da escola } \\
\text { (informática, vídeo, brinquedoteca/biblioteca) }\end{array}$ & 4 & 3 & 2 & 24 & $4^{0}$ \\
\hline $\begin{array}{l}\text { Necessidade de um acervo maior de livros na } \\
\text { escola }\end{array}$ & 3 & 3 & 2 & 18 & $5^{0}$ \\
\hline
\end{tabular}

\section{Detalhamento do problema}

Utilizou-se o Diagrama de Causa e Efeito para detalhar o problema:

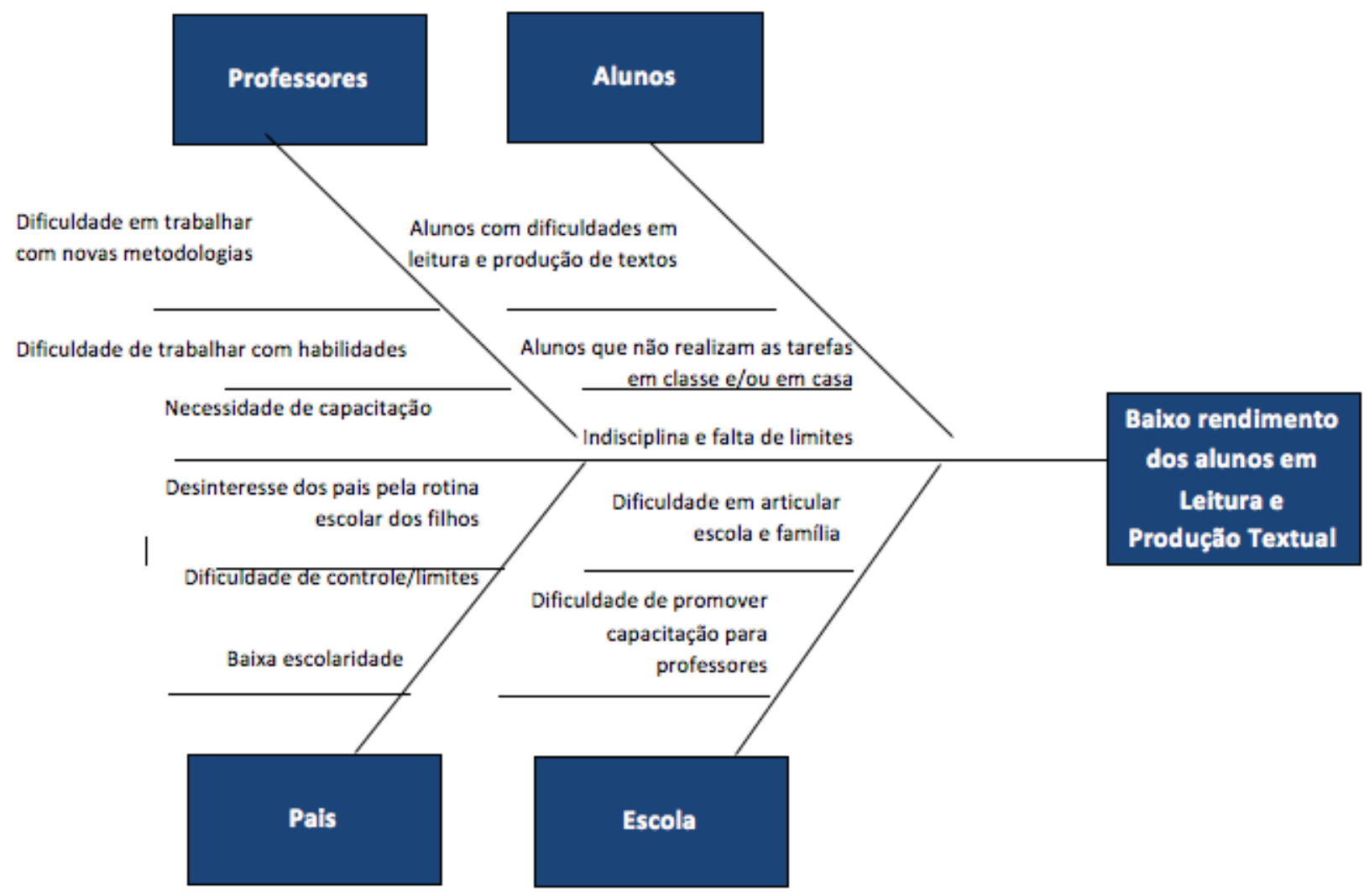




\section{Análise SWOT}

\begin{tabular}{|c|c|}
\hline Aspectos favoráveis & Aspectos desfavoráveis \\
\hline FORÇAS & FRAQUEZAS \\
\hline $\begin{array}{l}\text { 1. Participação significativa das famílias nos eventos } \\
\text { e festividades desenvolvidos pela escola. } \\
\text { 2. Profissionais comprometidos com os alunos e } \\
\text { receptivos a mudanças. } \\
\text { 3. Utilização adequada dos recursos financeiros da } \\
\text { escola, em prol da melhoria das instalações físicas, e } \\
\text { de ensino-aprendizagem dos alunos. } \\
\text { 4. Quadro completo de profissionais de apoio. } \\
\text { 5. Vários ambientes de aprendizagem: sala de } \\
\text { informática, brinquedoteca/ biblioteca, sala de vídeo, } \\
\text { etc. }\end{array}$ & $\begin{array}{l}\text { 1. Deficiências na formação inicial do professor. } \\
\text { 2. Dificuldades na implantação do currículo oficial e } \\
\text { na utilização dos materiais do Ler e Escrever } \\
\text { (Língua Portuguesa) e EMAI (Matemática). } \\
\text { 3. Dificuldades de comunicação entre os membros } \\
\text { da escola. } \\
\text { 4. Pouca participação efetiva dos pais no } \\
\text { acompanhamento diário da vida escolar do aluno. } \\
\text { 5. Alunos desmotivados e desinteressados. } \\
\text { 6. Alunos com problemas de disciplina/limites. }\end{array}$ \\
\hline OPORTUNIDADES & AMEAÇAS \\
\hline $\begin{array}{l}\text { 1. Proximidades com Postos de Saúde, Batalhão da } \\
\text { Polícia Militar, Grandes Avenidas, Monotrilho e } \\
\text { comércio local. } \\
\text { 2. A maioria dos alunos mora no entorno da escola } \\
\text { facilitando o contato com as famílias. } \\
\text { 3. Parcerias com a Polícia Militar (PROERD), Postos } \\
\text { de Saúde, Metrô e Grupo de Escoteiros Yapira. }\end{array}$ & $\begin{array}{l}\text { 1. Risco Social (vulnerabilidade). } \\
\text { 2. Desagregação familiar com prejuízo na vida } \\
\text { escolar dos alunos. } \\
\text { 3. Cerca de } 30 \% \text { das famílias possui renda familiar } \\
\text { muito baixa. } \\
\text { 4. Desinteresse dos pais pela aprendizagem dos } \\
\text { alunos. }\end{array}$ \\
\hline
\end{tabular}

Analisando a Matriz SWOT da escola, verificamos que possuímos profissionais comprometidos com a escola e receptivos a mudanças, além de pais que participam significativamente nos eventos e festividades realizados pela escola. A escola conta também com vários ambientes e materiais que podem ser utilizados no auxílio das aprendizagens (Forças). A escola encontra-se bem situada no bairro e contamos excelentes parcerias que nos auxiliam no trabalho com os alunos (Oportunidades).

A maior necessidade é capacitar os professores para trabalharem com aulas diversificadas e com o Material do Ler e Escrever e para que desenvolvam nos alunos as habilidades necessárias para uma melhora significativa na leitura e escrita dos mesmos. Um dos nossos desafios é conseguir o auxílio das famílias no sentido de incentivarem e participarem efetivamente da vida escolar dos alunos (Fraquezas e Ameaças).

\section{Ações corretivas}

Visando preparar a organização para o desenvolvimento do projeto, no intuito de combater as fraquezas e reduzir os possíveis impactos das ameaças, foram definidas as seguintes ações:

- Elaboração coletiva pelo grupo gestor e docentes de Projeto que trabalhe as dificuldades dos alunos (ênfase em leitura e escrita)

- Programa de Capacitação dos docentes, enfatizando o trabalho com novas metodologias, conteúdos e habilidades.

\section{- Capacitação de uso de Novas Tecnologias}

- Reuniões para a elaboração, discussão e análise das atividades desenvolvidas e para troca de experiência entre os docentes

- Elaboração coletiva pelos docentes de avaliações internas que serão aplicadas na escola

- Utilização de outros ambientes e materiais de aprendizagem: sala de informática, sala de vídeo e 
brinquedoteca/biblioteca.

- Reuniões e atividades com pais conscientizando-os da necessidade de participação na vida escolar dos filhos.

\section{Oportunidade identificada}

Após a realização de reunião de estudos abordando os principais problemas diagnosticados, a equipe de gestores e professores da escola decidiu pela elaboração de Projeto que envolva alunos e pais, e que tenha como enfoque a melhoria da leitura e escrita dos alunos e um comprometimento maior das famílias na vida escolar dos filhos.

O trabalho será realizado com a aplicação de metodologias inovadoras em sala de aula enfocando as habilidades dos alunos. Para atingir tal objetivo os professores serão capacitados e terão reuniões para desenvolverem conjuntamente atividades e avaliações. Os alunos e pais também terão reuniões e oficinas que serão realizadas aos sábados, com o objetivo de participarem de atividades que possam auxiliá-los no acompanhamento dos filhos.

Esse projeto visa minimizar os problemas diagnosticados no diagrama de causa e efeito e na matriz SWOT. As ações são integradas e ao final de cada ano esperamos uma melhoria significativa nos índices de desempenho dos alunos, tanto nas avaliações internas, quanto externas.

\section{Detalhamento do produto/serviço e/ou processo}

O Projeto "Vivenciando o Prazer da Leitura" oportuniza um trabalho integrado entre gestores, professores, alunos e pais. Trabalharemos com enfoque nos principais problemas diagnosticados na escola através um projeto que envolva a leitura e escrita dos alunos, capacitação de professores e participação das famílias na vida escolar dos filhos. Nosso objetivo principal é obter um avanço significativo nos níveis de desempenho dos alunos relacionados à leitura e produção textual.

\section{Foco do projeto}

Série ou conjunto de séries beneficiadas: Alunos do $1^{\circ}$ ao $5^{\circ}$ ano das séries iniciais.

Disciplina ou conjunto de disciplinas trabalhadas: Língua Portuguesa.

\section{Etapas do projeto}

O projeto será composto pelas seguintes etapas:

\section{Etapa 1 - Conhecendo e articulando o Projeto.}

Objetivo: Conhecimento do Projeto pela Equipe Escolar e Capacitação de Professores.

Impacto na aprendizagem: Obter avanços significativos nos níveis de desempenho de leitura e escrita dos alunos. A capacitação dos professores irá facilitar o processo de ensino e aprendizagem dos alunos.

Atividades a serem realizadas: Reunião para conhecimento e discussão/organização do Projeto e Capacitação dos professores.

\section{Atividade 1.1}

Descrição: Reunião com a Equipe de Gestores e professores para conhecer o Projeto, discutir as etapas que serão desenvolvidas, realizar as adaptações necessárias, esclarecer dúvidas e montar cronograma de capacitação dos professores e oficinas com pais e alunos.

Duração: 4 horas/aula no mês de fevereiro.

Recursos necessários: Computador e Data Show.

Equipe envolvida: Equipe Gestora (Diretor, Vice-diretor e professor coordenador) e professores.

\section{Atividade 1.2}


Descrição: Os professores terão quatro reuniões de capacitação, onde serão trabalhados: uso do material do Ler e Escrever, metodologias e estratégias de ensino, habilidades e competências, aulas de leitura utilizando diversidade textual e orientação para realização de oficinas de leitura com alunos e pais.

Duração: Quatro encontros de 4 horas/aula cada um nos meses de fevereiro, março, maio e agosto.

Recursos necessários: Data Show, Material do Ler e Escrever, Textos de apoio, acervo de livros da escola, jornais, sala de informática, etc.

Equipe envolvida: Equipe Gestora, Especialista em capacitação de professores (externo) e Professores.

\section{Etapa 2 - Momentos da leitura}

Objetivo: Trabalhar com diferentes gêneros textuais em sala de aula, propiciando oportunidade para que os alunos acessem um novo modo de construir a linguagem que se diferencia daquele que se usa no cotidiano.

Impacto na aprendizagem: 0 trabalho com diferentes gêneros textuais amplia o vocabulário e a forma de construir orações, próprios aos textos escritos, propiciando novas experiências linguísticas para os alunos. Pela literatura entram em contato com realidades distintas, relativizando seu próprio ponto de vista e enriquecendo seus conhecimentos de outras épocas e lugares. Os contos clássicos apaixonam as crianças e ajudam-nas a lidar com diferentes sentimentos infantis.

Atividades a serem realizadas: Atividades de leitura realizadas diariamente pelo professor em sala de aula ( 1 hora/aula) e leitura para ser realizada em casa uma vez por semana.

\section{Atividade 2.1}

Descrição: A atividade de leitura em voz alta pelo professor deve ocorrer diariamente com prioridade para textos da esfera literária como contos de fada e populares, mitos, etc. Uma vez por semana é possível incluir a leitura de textos de divulgação científica, como verbetes em geral e textos explicativos. Deve selecionar livros com boas histórias, com bom enredo e que sejam interessantes, visando aproximar a criança da literatura. Deverá incluir nas aulas diversos gêneros textuais, trabalhando com cantigas, receitas de culinária, cartas, bilhetes, jogos, anúncios e convites.

O professor deve explicar a atividade que será realizada para os alunos. Quando fizer a leitura dos livros deve informar o título do livro, mostrar a capa, os autores, ilustradores e editora. Propor que imaginem do que se trata a história, momento importante para instigar a curiosidade dos alunos. Ao ler a história o professor pode realizar pequenas interrupções para que os alunos digam o que acham que acontecerá. Ler até o final e mostrar as ilustrações aos alunos. O professor também pode utilizar a sala de informática, pois poderá realizar atividades com histórias, jornal, receitas e cantigas que serão pesquisadas pelos alunos. Quando utiliza o jornal, o professor mostra as principais partes do mesmo e as notícias em destaque. Pode fazer recortes das notícias recentes e montar um mural na sala de aula.

Duração: 1hora/aula por dia, cinco dias na semana.

Recursos necessários: Livros de histórias, jornais, revistas e sala de informática.

Equipe envolvida: Professores e alunos.

\section{Atividade 2.2}

Descrição: Todas as sextas feiras cada aluno levara um livro para ler em casa, junto à família. Cada aluno confeccionará uma sacola decorada onde levará o livro de sua escolha para ser lido durante o final de semana. A confecção será realizada na aula de arte, com orientação do professor da área (2 horas/aula). No retorno à escola, alguns alunos deverão contar em sala de aula para os demais a história que leram e todos deverão realizar uma atividade onde anotarão as seguintes informações: nome do livro, autor, editora, principais personagens e parte de que mais gostou. Os alunos menores que ainda têm muita dificuldade na escrita poderão desenhar a história e dar as informações oralmente, com a ajuda do professor.

Duração: Semanalmente, uma hora para leitura com a família e uma hora/aula em sala de aula para realizar a 
socialização da leitura que foi realizada em casa com o professor e colegas da sala.

Recursos necessários: Sacolas decoradas e livros do acervo da escola.

Equipe envolvida: Professores, alunos e pais (ou outros familiares).

\section{Etapa 3 - Palestra para os pais e Oficinas com professores, alunos e pais.}

Objetivo: Conscientizar os pais da importância do acompanhamento e incentivo na vida escolar dos filhos.

Impacto na aprendizagem: Desenvolver uma maior consciência nos pais sobre a importância de acompanhar as atividades desenvolvidas pelos filhos na escola e com isso conseguir uma maior participação dos pais na vida escolar dos mesmos, motivando a aprendizagem dos filhos.

Atividades a serem realizadas: Palestra de conscientização com os pais e oficinas de leitura e contação de histórias, cantigas de roda, jornal e receitas de culinária com alunos e pais. As oficinas serão adaptadas pelos professores para cada ano de ensino.

\section{Atividade 3.1}

Descrição: A palestra de conscientização "Importância do acompanhamento e participação na vida escolar dos filhos" será realizada num sábado por profissional contratado da área de psicologia que fará a exposição aos pais sobre a necessidade da participação dos mesmos no acompanhamento da vida escolar de seus filhos. Em seguida o Diretor da escola apresentará o projeto de leitura e escrita que será desenvolvido com todos os alunos da escola, e das oficinas que serão realizadas aos sábados com alunos e pais.

Duração: 3 horas/aula realizadas num sábado no mês de março.

Recursos necessários: Data show, equipamentos de som e vídeo.

Equipe envolvida: Equipe gestora, palestrante, professores e pais.

\section{Atividade 3.2 - Oficina 1 - Leitura e Contação de histórias}

Descrição: Socializar com os pais o trabalho com leitura realizado na escola e desenvolver com os alunos e pais atividades para 0 incentivo da leitura. 0 professor pode fazer uma leitura do acervo para os pais demonstrando como realiza a atividade em sala de aula. No momento posterior os alunos podem ler ou contar histórias já ouvidas para os pais, manuseando os livros escolhidos. Os pais também podem escolher livros do acervo para ler com toda a turma ou com os filhos, realizar dramatizações com fantoches e dedoches, etc. Os alunos dos $5^{\circ}$ anos montarão um Blog com histórias para serem compartilhadas, e parte das atividades da oficina poderão ser desenvolvidas na sala de informática. Os pais relatam suas impressões sobre as atividades da oficina e expõem no mural da escola.

Duração: 3 horas/aula realizadas num sábado no mês de abril.

Recursos necessários: Acervo de livros, fantoches, dedoches, materiais para confecção de máscaras e fantasias, sala de informática.

Equipe envolvida: Equipe Gestora, professores, alunos e pais.

\section{Atividade 3.3 - Oficina 2 - Roda da Música}

Descrição: Nesse dia estarão expostos nos espaços da escola as cantigas trabalhadas pelos professores em sala de aula. Os professores socializarão as atividades realizadas em sala de aula com cantigas. Demonstrarão como foi realizado o trabalho com a estrutura (a letra da música), significado das palavras (uso do dicionário), versos e estrofes. Os alunos dos $1^{\circ}$ e $2^{\circ}$ anos poderão realizar brincadeiras de roda, resgatando cantigas da infância dos pais, que serão ensinadas pelos mesmos. Os $3^{\circ}, 4^{\circ}$ e $5^{\circ}$ anos poderão apresentar musicas antigas com instrumentos musicais. Em todas as oficinas poderão ser confeccionados instrumentos musicais e utilizados para cantar. Pais e alunos que tocam instrumentos poderão levá-los para tocar e cantar junto com o grupo. Os pais relatam suas impressões sobre as atividades da oficina e expõem no mural da escola. 
Duração: 3 horas/aula realizadas num sábado no mês de maio.

Recursos necessários: Material do Ler e Escrever, livros e vídeos com cantigas, material para confeç̧ão de cartazes, material para confecção de instrumentos musicais, bandinha da escola.

Equipe envolvida: Equipe Gestora, professores, pais e alunos.

\section{Atividade 3.4 - Oficina 3 - Explorando o jornal}

Descrição: Os professores realizarão as oficinas trabalhando as notícias dos jornais, importância de ler e se interarem dos fatos e assuntos apresentados no jornal. Mostrarão as partes que compõem o jornal, manchetes e notícias em destaque. Poderão recortar notícias, confeccionar um jornal com a ajuda dos pais e expor os trabalhos nos murais da escola.

Duração: 3 horas/aula realizadas num sábado no mês de agosto.

Recursos necessários: Diversos jornais atuais, cola, tesoura, cartolinas, canetas coloridas, papel sulfite e outros materiais para a confecção de jornais.

Equipe envolvida: Equipe gestora, professores, pais e alunos.

\section{Atividade 3.5 - Oficina 4 - Receitas de culinária}

Descrição: Nesse dia estarão expostos nos espaços da escola as receitas de culinária e alimentação saudável trabalhadas pelos professores em sala de aula. 0 professor socializa com os pais 0 trabalho realizado em sala de aula com os alunos enfocando a análise textual das receitas culinárias, hábitos saudáveis de alimentação, pesquisas de receitas em livros, em cadernos de receitas da família e internet. No momento seguinte os alunos e pais escrevem as receitas de saladas e saladas de frutas junto com os alunos, preparam as receitas e montam um mural. Finalizam com um momento de degustação.

Duração: 3 horas/aula realizadas num sábado no mês de setembro.

Recursos necessários: ingredientes para preparação de saladas e salada de frutas, potinhos e talheres descartáveis para a degustação, cartolinas, pincel atômico, e fita crepe.

Equipe envolvida: Equipe Gestora, professores, pais e alunos.

\section{Etapa 4 - Avaliação do projeto}

Objetivo: Avaliação do projeto, correções e adaptações para os anos posteriores.

Impacto na aprendizagem: Verificar os avanços no desempenho em leitura e escrita dos alunos.

Atividades a serem realizadas: Reunião com a equipe gestora e professores para avaliar o projeto, verificar se as metas foram atingidas e efetuar as devidas correções e adaptações para a continuidade nos anos seguintes.

\section{Atividade 4.1}

Descrição: Será realizada reunião com a equipe gestora e professores para avaliar o projeto, verificar se as metas foram atingidas e efetuar as devidas correções e adaptações para a continuidade nos anos seguintes.

Duração: 4 horas/aula realizadas num sábado no mês de novembro.

Recursos necessários: Computador e Data show

Equipe envolvida: Equipe gestora e professores.

\section{Casos de sucesso}

Nome do Projeto: "Literar é só começar".

Nome da organização: Escola Municipal Alexandre Pereira Lima.

Local: Senador Canedo (GO). 
Período em que foi realizado: durante o ano de 2013.

\section{Breve relato do contexto anterior ao projeto:}

A professora Silvia Gonçalves relata que quando assumiu a turma do $2^{\circ}$ ano $\mathrm{F}$ percebeu que os alunos estavam desmotivados e a maioria não sabia ler nem escrever.

\section{Principais atividades desenvolvidas:}

- Aulas de contação de histórias;

- Trabalho com literatura em sala de aula;

- Modificação de hábitos familiares, apresentando livros de obras de arte aos pais;

- Releitura dos livros de obras de arte, desenvolvendo o trabalho em diálogo com outras disciplinas;

- Confecção de "sacolas literárias mágicas" para que o aluno levasse semanalmente o livro para casa e compartilhasse a leitura com os pais;

- Atividades pedagógicas lúdicas e artísticas desenvolvidas em diversos espaços da escola e ao ar livre;

\section{Resumo dos principais resultados alcançados:}

O Projeto motivou os alunos melhorando significativamente o desempenho escolar e o resultado da Provinha Brasil. Todos os alunos saíram alfabetizados. Além disso, os alunos puderam desenvolver o sentido de cidadania.

Fonte: http://portaldoprofessor.mec.gov.br/storage/materiais/0000016866.pdf

Nome do Projeto: Projeto Sala de Leitura "Da Emoção de Ler a Descoberta do Prazer"

Nome da organização: Escola Municipal D. Ângelo Frosi

Local: Abaetetuba (PA)

Período em que foi realizado: Durante o ano de 2013

\section{Breve relato do contexto anterior ao projeto:}

Muitos alunos da escola liam pouco ou quase nada. Havia muito desinteresse nas atividades que envolviam leitura. Muitos alunos decodificavam as palavras sem compreender o significado do texto lido. Tudo isso refletia no baixo rendimento do aluno e consequentemente na qualidade do ensino.

Principais atividades desenvolvidas:

- Apresentação do Projeto a comunidade escolar;

- Rodas de conversas;

- Apresentação e esclarecimento de dúvidas para os alunos da sala de leitura;

- Construção coletiva do contrato social (regras de convivência);

- Reconhecimento do espaço da sala de leitura e dos acervos existentes;

- Hora dos vídeos;

- Exposição oral e escrita das leituras lidas e ouvidas;

- Divulgação dos acervos literários para o empréstimo de livros;

- Instauração da sala de leitura itinerante;

- Gincana da leitura;

- Reescrita de textos lidos e ouvidos; 
- Oficinas de leitura;

- Produção de textos através da escrita e do desenho;

- Debates sobre leituras;

- Oficinas de redação;

- A hora do conto;

- Sarau de poesias;

- Fazendo poesias: varal;

- Teatro de fantoches;

- Dramatizações;

- O dia da leitura na escola (pais e alunos);

- Ler e contar histórias em voz alta, usando a modalidade escrita, etc.

- Auto-avaliação.

\section{Resumo dos principais resultados alcançados:}

Os resultados foram obtidos através da avaliação do envolvimento e interesse dos alunos, tendo como objetivo principal avançar nas habilidades ligadas a leitura, interpretação e produção de texto.

Fonte: http://escoladomangelofrosi.blogspot.com.br/2013/04/projeto-sala-de-leitura-da-emocao-de.html

\section{Novidade trazida pelo projeto}

O projeto é inovador para a escola pois articula ações que visam corrigir as principais dificuldades diagnosticadas: dificuldades na leitura e escrita dos alunos, necessidade de capacitação dos professores, pouca participação dos pais na rotina escolar dos filhos e pouca utilização de espaços e acervos de livros da escola.

O enfoque do projeto é incrementar a leitura no âmbito escolar, através do trabalho com novas estratégias de ensino e diversidade textual, enriquecendo a rotina escolar e estimulando a leitura e produção de texto escrito e oral. Espera-se com esse trabalho articulado um avanço significativo nos níveis de desempenho dos alunos em todas as disciplinas uma vez que a leitura e escrita são imprescindíveis para a compreensão das demais áreas de ensino.

\section{Cronograma de execução}

\begin{tabular}{|l|l|l|l|l|l|l|l|l|l|l|l|l|}
\hline \multirow{3}{*}{ Atividades } & \multicolumn{1}{|l|}{ Ano 1} & Ano 2 & \multicolumn{1}{l|}{ Ano 3} \\
& Jan- & Abr- & Jul- & Out- & Jan- & Abr- & Jul- & Out- & Jan- & Abr- & Jul- & Out- \\
& Mar & Jun & Set & Dez & Mar & Jun & Set & Dez & Mar & Jun & Set & Dez \\
\hline
\end{tabular}




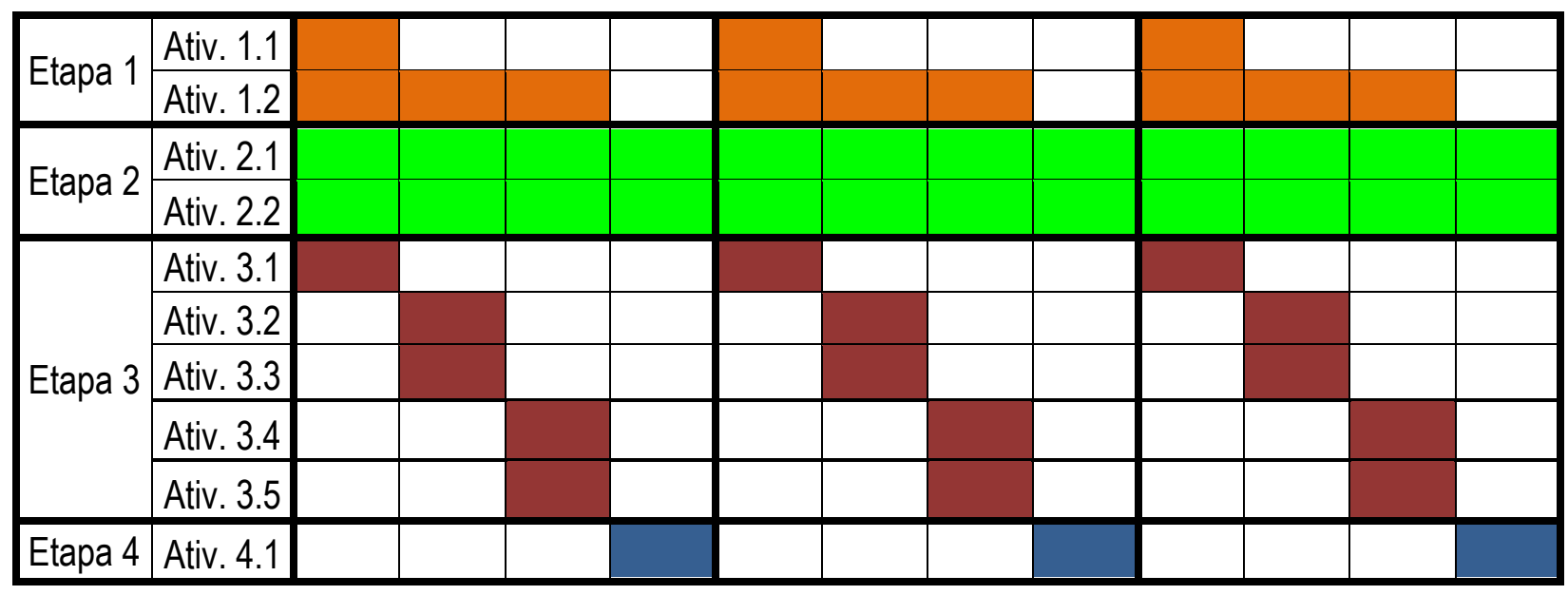

Gestão Estratégica

Objetivos estratégicos

\begin{tabular}{|c|c|c|c|}
\hline Objetivos & Metas & Indicadores & Acompanhamento \\
\hline \multirow{3}{*}{$\begin{array}{l}\text { 1. Aumentar o } \\
\text { nível de } \\
\text { desempenho dos } \\
\text { alunos em } \\
\text { Língua } \\
\text { Portuguesa e } \\
\text { Redação }\end{array}$} & $\begin{array}{l}\text { Aumentar a aprendizagem } \\
\text { dos alunos em Língua } \\
\text { Portuguesa ( leitura e } \\
\text { escrita) em } 10 \% \text { ao final do } \\
\text { primeiro ano de projeto; } \\
15 \% \text { no segundo ano e } 20 \% \\
\text { no terceiro. }\end{array}$ & $\begin{array}{l}\text { Resultado das } \\
\text { avaliações } \\
\text { internas de } \\
\text { Língua } \\
\text { Portuguesa, das } \\
\text { avaliações das } \\
\text { plataformas } \\
\text { Meritt e Sara, e } \\
\text { das avaliações } \\
\text { externas } \\
\text { SARESP e Prova } \\
\text { Brasil. }\end{array}$ & $\begin{array}{l}\text { Controle bimestral do } \\
\text { rendimento das turmas e } \\
\text { definição de ações corretivas } \\
\text { para o planejamento (caso seja } \\
\text { necessário), levando em } \\
\text { consideração também o } \\
\text { feedback de alunos e } \\
\text { professores. }\end{array}$ \\
\hline & $\begin{array}{l}\text { Alcançar a meta } \\
\text { estabelecida nas avaliações } \\
\text { externas SARESP e Prova } \\
\text { Brasil para Língua } \\
\text { Portuguesa até o final do } \\
\text { projeto. }\end{array}$ & $\begin{array}{l}\text { Resultado das } \\
\text { avaliações } \\
\text { externas } \\
\text { SARESP e Prova } \\
\text { Brasil para o ano } \\
\text { de } 2017 .\end{array}$ & $\begin{array}{l}\text { Análise das habilidades } \\
\text { necessárias nos ATPCs. } \\
\text { Discussão e estabelecimento } \\
\text { de ações específicas com base } \\
\text { nas avaliações internas, e } \\
\text { externas. }\end{array}$ \\
\hline & $\begin{array}{l}\text { Aumentar o número de } \\
\text { buscas (empréstimos) por } \\
\text { livros do acervo da escola } \\
\text { em } 20 \% \text { no final do primeiro } \\
\text { ano de projeto; } 40 \% \text { no } \\
\text { segundo ano e } 50 \% \text { no } \\
\text { terceiro. }\end{array}$ & $\begin{array}{l}\text { Ficha de } \\
\text { empréstimo dos } \\
\text { livros. }\end{array}$ & $\begin{array}{l}\text { Reuniões mensais com o } \\
\text { professor responsável pelo } \\
\text { acervo de leitura e com o } \\
\text { professor de cada turma. }\end{array}$ \\
\hline
\end{tabular}




\begin{tabular}{|c|c|c|c|}
\hline \multirow{3}{*}{$\begin{array}{l}\text { 2. Aumentar o } \\
\text { acompanhamento } \\
\text { dos pais na rotina } \\
\text { diária escolar dos } \\
\text { filhos. }\end{array}$} & $\begin{array}{l}\text { Aumentar o número de pais } \\
\text { que participam das reuniões } \\
\text { de pais e mestres em } 30 \% \\
\text { no final do primeiro ano de } \\
\text { projeto, } 40 \% \text { no segundo } \\
\text { ano e } 50 \% \text { no terceiro ano }\end{array}$ & $\begin{array}{l}\text { Número de pais } \\
\text { que participam } \\
\text { das reuniões de } \\
\text { pais e mestres. }\end{array}$ & $\begin{array}{l}\text { Controle bimestral do número } \\
\text { de participantes das reuniões. } \\
\text { Convocar os pais que não } \\
\text { compareceram para } \\
\text { atendimento individual. }\end{array}$ \\
\hline & $\begin{array}{l}\text { Aumentar o } \\
\text { acompanhamento dos pais } \\
\text { na rotina diária escolar dos } \\
\text { filhos em } 30 \% \text { no final do } \\
\text { primeiro ano de projeto, } \\
40 \% \text { no segundo ano e } 50 \% \\
\text { no terceiro ano. }\end{array}$ & $\begin{array}{l}\text { Número de pais } \\
\text { que participam } \\
\text { das reuniões de } \\
\text { pais e oficinas de } \\
\text { leitura. } \\
\text { Depoimento dos } \\
\text { pais nas reuniões } \\
\text { de pais e } \\
\text { mestres. }\end{array}$ & $\begin{array}{l}\text { Levantamento mensal do } \\
\text { número de pais participantes } \\
\text { nas reuniões e oficinas. } \\
\text { Relatório mensal contendo os } \\
\text { depoimentos dos pais em } \\
\text { relação ao acompanhamento } \\
\text { da rotina escolar dos filhos }\end{array}$ \\
\hline & $\begin{array}{l}\text { Promover e aumentar a } \\
\text { participação dos pais na } \\
\text { Palestra de } \\
\text { Conscientização e oficinas } \\
\text { de leitura com alunos e pais } \\
\text { em } 30 \% \text { no final do primeiro } \\
\text { ano de projeto, } 40 \% \text { no } \\
\text { segundo ano e } 50 \% \text { no } \\
\text { terceiro ano }\end{array}$ & $\begin{array}{l}\text { Número de pais } \\
\text { que participaram } \\
\text { da Palestra de } \\
\text { Conscientização } \\
\text { e oficinas de } \\
\text { leitura com } \\
\text { alunos e pais. }\end{array}$ & $\begin{array}{l}\text { Levantamento mensal do } \\
\text { número de pais participantes. } \\
\text { Divulgação contínua dessas } \\
\text { atividades para os pais, com o } \\
\text { objetivo de obter um número } \\
\text { maior de participantes. }\end{array}$ \\
\hline
\end{tabular}

\begin{tabular}{|c|c|c|c|}
\hline Objetivos & Metas & Indicadores & Acompanhamento \\
\hline \multirow{2}{*}{$\begin{array}{l}\text { 3. Capacitar os } \\
\text { professores } \\
\text { para utilizarem } \\
\text { novas } \\
\text { metodologias e } \\
\text { estratégias } \\
\text { diversificadas } \\
\text { de ensino. }\end{array}$} & $\begin{array}{l}\text { Desenvolver habilidades e } \\
\text { competências de leitura e } \\
\text { escrita nos alunos, } \\
\text { melhorando o desempenho } \\
\text { em } 10 \% \text { ao final do primeiro } \\
\text { ano de projeto; } 15 \% \text { no } \\
\text { segundo ano e } 20 \% \text { no } \\
\text { terceiro. }\end{array}$ & $\begin{array}{l}\text { Avaliações } \\
\text { internas de } \\
\text { Língua } \\
\text { Portuguesa, } \\
\text { resultados das } \\
\text { avaliações das } \\
\text { plataformas } \\
\text { Meritt e Sara, e } \\
\text { das avaliações } \\
\text { externas } \\
\text { SARESP e Prova } \\
\text { Brasil. }\end{array}$ & $\begin{array}{l}\text { Controle bimestral do } \\
\text { rendimento das turmas e } \\
\text { definição de ações corretivas } \\
\text { para o planejamento (caso seja } \\
\text { necessário), levando em } \\
\text { consideração também o } \\
\text { feedback de alunos e } \\
\text { professores. }\end{array}$ \\
\hline & $\begin{array}{l}\text { Diversificar as estratégias } \\
\text { de ensino tornando as aulas } \\
\text { mais atraentes. }\end{array}$ & $\begin{array}{l}\text { Observação das } \\
\text { aulas pelo } \\
\text { professor } \\
\text { coordenador e } \\
\text { pesquisa de } \\
\text { satisfação das } \\
\text { aulas com alunos } \\
\text { e pais. }\end{array}$ & $\begin{array}{l}\text { Análise das aulas } \\
\text { acompanhadas pelo professor } \\
\text { coordenador e da pesquisa } \\
\text { realizada. Socialização dos } \\
\text { resultados em reuniões de } \\
\text { ATPCs. }\end{array}$ \\
\hline
\end{tabular}




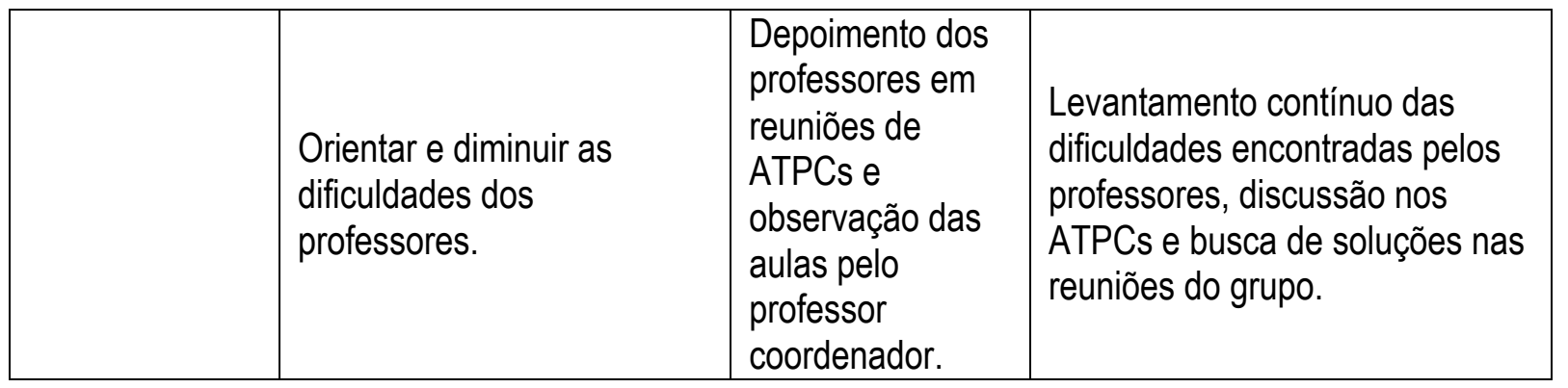

\section{Continuidade do projeto}

Este Projeto deverá ser executado por um período de três anos, dê acordo com o cronograma de execução. Existe anualmente na escola uma pequena rotatividade de professores em cada ano letivo. Desse modo os professores novos serão engajados no projeto e devidamente orientados nas reuniões pedagógicas, capacitações e ATPCs.

Os alunos iniciam o Projeto no início de cada ano letivo e contarão com a participação dos pais nas palestras e oficinas. Pretende-se criar uma cultura de leitura e escrita na escola com o acompanhamento das famílias. O acompanhamento deverá ser contínuo para evitar que os resultados alcançados voltem a cair. Na verdade, a tendência é a continuidade das ações após os três anos iniciais do Projeto.

\section{Marketing e Comunicação}

\section{Lançamento do projeto}

A primeira ação do projeto será a divulgação para a Equipe Escolar numa reunião de conhecimento e discussão do Projeto com detalhamento de suas ações, etapas, acompanhamento e avaliação. A equipe gestora e os professores discutirão as três etapas que serão desenvolvidas: Conhecimento do Projeto pela Equipe Escolar e Capacitação de Professores, Momentos da leitura em sala de aula e na casa do aluno e Palestra de Conscientização com os pais e oficinas de leitura para alunos e pais.

A divulgação para os pais será através de uma Palestra de Conscientização "Importância do acompanhamento e participação na vida escolar dos filhos" realizada por um psicólogo com convite estendido aos pais e familiares dos alunos. $O$ convite será feito através de folder explicativo levado aos pais pelos alunos. Após a Palestra o Diretor da Escola apresentará o Projeto de Leitura e Escrita que será desenvolvido com todos os alunos da escola e as oficinas que serão realizadas aos sábados com alunos e pais. $A$ divulgação do projeto será contínua através de avisos nas reuniões de pais e mestres, murais, cartazes, avisos na agenda dos alunos, facebook e blog da Escola.

\section{Canais de comunicação e acompanhamento do projeto}

\section{Marketing interno}

A Equipe gestora e os professores envolvidos utilizarão reuniões pedagógicas e parte dos horários de ATPCs para 0 acompanhamento do projeto. Nesses encontros serão utilizados vídeos, dinâmicas de grupos, discussões e troca de experiências com o objetivo de integrar e incentivar os envolvidos facilitando a realização das ações propostas no projeto. Será criado um e-mail para troca de informações e esclarecimentos de dúvidas entre os membros do grupo. As atividades diárias do Projeto em sala de aula com os alunos serão discutidas semanalmente. Mensalmente serão debatidas as capacitações dos professores e oficinas com pais e alunos. As discussões nortearão o trabalho do grupo. Informações do Projeto serão colocadas mensalmente em cartazes e murais.

\section{Marketing externo}

Durante o desenvolvimento do Projeto a comunicação com os pais será através de reuniões de pais e mestres onde os professores farão uma síntese das ações que estão sendo desenvolvidas e os resultados 
observados. Os trabalhos realizados no período ficarão expostos em murais, assim como fotos das atividades desenvolvidas. Os mesmos poderão acompanhar o cronograma de atividades e as ações desenvolvidas através do facebook e blog da escola.

\section{Parceiros estratégicos}

A escola não utilizará serviços ou recursos de parceiros externos.

\section{Divulgação de resultados}

Os resultados parciais do projeto serão divulgados bimestralmente e na quarta etapa será feita a avaliação anual do projeto. Esses dados primeiramente serão analisados pela Equipe Escolar e posteriormente divulgados nas reuniões de pais e mestres durante 0 ano letivo, facebook, murais e blog da escola. $O$ objetivo da análise é divulgar os avanços obtidos com a implementação do Projeto e nortear as ações que serão desenvolvidas posteriormente.

\section{Equipe do projeto}

Equipe interna

\begin{tabular}{|l|l|l|l|l|}
\hline Cargo & Formação & $\begin{array}{l}\text { Tempo na } \\
\text { escola }\end{array}$ & Experiência anterior & $\begin{array}{l}\text { Responsável } \\
\text { pelas } \\
\text { atividades: }\end{array}$ \\
\hline Diretor & Pedagogia & 4 anos & Professor e Diretor & $\begin{array}{l}\text { Coordenar } \\
\text { todas as etapas } \\
\text { do Projeto }\end{array}$ \\
\hline Vice Diretor & Pedagogia & 5 anos & Professor & $\begin{array}{l}\text { Coordenar } \\
\text { todas as etapas } \\
\text { do Projeto }\end{array}$ \\
\hline $\begin{array}{l}\text { Professor } \\
\text { Coordenador }\end{array}$ & $\begin{array}{l}\text { Magistério e/ou } \\
\text { Pedagogia }\end{array}$ & 8 anos & Professor & $\begin{array}{l}\text { Coordenar } \\
\text { todas as etapas } \\
\text { do Projeto }\end{array}$ \\
\hline $\begin{array}{l}\text { Professores das } \\
\text { turmas (27) }\end{array}$ & $\begin{array}{l}\text { Magistério elou } \\
\text { Pedagogia }\end{array}$ & $\begin{array}{l}1 \text { ano até } \\
20 \text { anos }\end{array}$ & Professor & $\begin{array}{l}\text { Etapa 2 } \\
\text { (atividades } \\
\text { 2.1/2.2) e } \\
\text { Etapa 3 } \\
\text { (atividades } \\
3.2 / 3.3 / 3.4 / 3.5)\end{array}$ \\
\hline $\begin{array}{l}\text { Professores de } \\
\text { arte (02) }\end{array}$ & Arte & $\begin{array}{l}2 \text { até 7 } \\
\text { anos }\end{array}$ & Professor & Atividade 2.2 \\
\hline
\end{tabular}




\section{Mariangela Tschisar}

\section{Profissionais externos}

\begin{tabular}{|l|l|l|}
\hline Tipo de profissional & Competências necessárias & Participação no projeto \\
\hline Psicólogo & $\begin{array}{l}\text { Psicologia escolar e orientação } \\
\text { de pais }\end{array}$ & $\begin{array}{l}\text { Atividade 3.1 } \\
\text { Palestra de Conscientização } \\
\text { dos pais }\end{array}$ \\
\hline $\begin{array}{l}\text { Pedagogo } \\
\text { para capacitação de professores }\end{array}$ & $\begin{array}{l}\text { Conhecimentos em } \\
\text { desenvolvimento de Projetos } \\
\text { com Professores e em } \\
\text { metodologias e estratégias de } \\
\text { ensino diversificadas em sala } \\
\text { de aula. }\end{array}$ & \begin{tabular}{l} 
Capacitação de Professores. \\
\hline
\end{tabular} \\
\hline
\end{tabular}

\section{Plano financeiro}

Não temos necessidade de realização de obras na escola.

\begin{tabular}{|l|l|l|l|}
\hline Material permanente & Ano 1 & Ano 2 & Ano 3 \\
\hline Acervo de livros & $7.000,00$ & $7.000,00$ & $7.000,00$ \\
\hline $\begin{array}{l}\text { Apostilas para capacitação de } \\
\text { professores }\end{array}$ & 500,00 & 500,00 & 500,00 \\
\hline Total & $\mathbf{7 . 5 0 0 , 0 0}$ & $\mathbf{7 . 5 0 0 , 0 0}$ & $\mathbf{7 . 5 0 0 , 0 0}$ \\
\hline
\end{tabular}

\section{Despesas correntes}

Os serviços prestados pelo diretor, vice-diretor, professor coordenador e professores (oficinas e acompanhamento das mesmas) nos sábados não letivos foram computados como serviços de terceiros e remunerados com a verba destinada ao projeto. Para esse cálculo foi utilizado o valor médio da hora/aula dos gestores e professores da própria escola (SEE do Estado de São Paulo).

\begin{tabular}{|l|l|l|l|}
\hline Material de consumo & Ano 1 & Ano 2 & Ano 3 \\
\hline $\begin{array}{l}\text { Material para confecção de } \\
\text { sacolas de leitura }\end{array}$ & $3.000,00$ & $3.000,00$ & $3.000,00$ \\
\hline $\begin{array}{l}\text { Materiais de papelaria para as } \\
\text { oficinas }\end{array}$ & $5.400,00$ & $5.400,00$ & $5.400,00$ \\
\hline Folders de divulgação & 600,00 & 600,00 & 600,00 \\
\hline Jornais para oficinas & 600,00 & 600,00 & 600,00 \\
\hline Alimentos para oficina de receitas & $1.000,00$ & $1.000,00$ & $1.000,00$ \\
\hline Total & $10.600,00$ & $10.600,00$ & $10.600,00$ \\
\hline
\end{tabular}

\begin{tabular}{|l|l|l|l|}
\hline Serviços de terceiros & Ano 1 & Ano 2 & Ano 3 \\
\hline Palestrante (Psicólogo) & 300,00 & 300,00 & 300,00 \\
\hline Professor Capacitador & $1.120,00$ & $1.120,00$ & $1.120,00$ \\
\hline $\begin{array}{l}\text { Oficinas realizadas pelos } \\
\text { professores }\end{array}$ & $4.860,00$ & $4.860,00$ & $4.860,00$ \\
\hline Diretor & 360,00 & 360,00 & 360,00 \\
\hline
\end{tabular}


Vivenciando o prazer da leitura

\begin{tabular}{|l|l|l|l|}
\hline Vice- diretor & 312,00 & 312,00 & 312,00 \\
\hline Professor coordenador & 264,00 & 264,00 & 264,00 \\
\hline Total & $\mathbf{7 . 2 1 6 , 0 0}$ & $\mathbf{7 . 2 1 6 , 0 0}$ & $\mathbf{7 . 2 1 6 , 0 0}$ \\
\hline
\end{tabular}

\section{Recursos do edital}

\begin{tabular}{|l|l|l|l|l|}
\hline Tipo de item & Ano 1 & Ano 2 & Ano 3 & Total \\
\hline Despesas de Capital & $\mathbf{7 . 5 0 0 , 0 0}$ & $\mathbf{7 . 5 0 0 , 0 0}$ & $\mathbf{7 . 5 0 0 , 0 0}$ & $\mathbf{2 2 . 5 0 0 , 0 0}$ \\
\hline Obras e infraestrutura & 0,00 & 0,00 & 0,00 & 0,00 \\
\hline Material permanente & $7.500,00$ & $7.500,00$ & $7.500,00$ & $22.500,00$ \\
\hline Despesas Correntes & $\mathbf{1 7 . 8 1 6 , 0 0}$ & $\mathbf{1 7 . 8 1 6 , 0 0}$ & $\mathbf{1 7 . 8 1 6 , 0 0}$ & $\mathbf{5 3 . 4 4 8 , 0 0}$ \\
\hline Material de consumo & $10.600,00$ & $10.600,00$ & $10.600,00$ & $31.800,00$ \\
\hline Gastos com locomoção & 0,00 & 0,00 & 0,00 & 0,00 \\
\hline Serviços de terceiros & $7.216,00$ & $7.216,00$ & $7.216,00$ & $21.648,00$ \\
\hline Total do projeto & $\mathbf{2 5 . 3 1 6 , 0 0}$ & $\mathbf{2 5 . 3 1 6 , 0 0}$ & $\mathbf{2 5 . 3 1 6 , 0 0}$ & $\mathbf{7 5 . 9 4 8 , 0 0}$ \\
\hline
\end{tabular}

\section{Contrapartida}

Foi considerado o trabalho da equipe interna em sete sábados letivos incluídos no calendário escolar para a reunião inicial do projeto, capacitação de professores, palestra de conscientização e divulgação do projeto e reunião de avaliação final do mesmo. Para esse cálculo foi utilizado o valor médio da hora/aula dos gestores e professores da própria escola (SEE do Estado de São Paulo).

O valor calculado no quadro é anual. O valor total para três anos será de 40.113,00.

\begin{tabular}{|l|l|l|l|}
\hline Profissionais & $\begin{array}{l}\text { Horas dedicadas } \\
\text { ao projeto }\end{array}$ & Valor médio/hora & $\begin{array}{l}\text { Contrapartida por } \\
\text { profissional }\end{array}$ \\
\hline Professores (27) & 27 & 15,00 & $\begin{array}{l}(27 \text { professores) } \\
10.935,00\end{array}$ \\
\hline Professores de arte (2) & 11 & 15,00 & $\begin{array}{l}(02 \text { professores) } \\
330,00\end{array}$ \\
\hline Diretor & 27 & 30,00 & 810,00 \\
\hline Vice-diretor & 27 & 26,00 & 702,00 \\
\hline Professor coordenador & 27 & 22,00 & 594,00 \\
\hline Total de contrapartida & 119 & $\mathbf{2 1 , 6 0}$ & $13.371,00$ \\
\hline
\end{tabular}

